\title{
Konsistensi Internal dan Validasi Kriteria pada Alat Ukur Kesehatan Mental Mahasiswa Universitas Hasanuddin
}

\section{Internal Consistency and Criteria Validity Mental Health Literacy Scale among College Students in Universitas Hasanuddin}

\author{
Yulita Sirinti Pongtambing, Dien Anshari ${ }^{2}$, Yoslien Sopamena ${ }^{3}$, \\ Wa Ode Sri Andriani ${ }^{4}$, Yessy Fitriani ${ }^{5}$ \\ 1-5Departemen Pendidikan Kesehatan dan Ilmu Perilaku, Fakultas Kesehatan Masyarakat, \\ Universitas Indonesia
}

\begin{abstract}
Mental health literacy is an important skill to improve mental health condition among late adolescents who are in their first year of higher education training. However, mental health literacy is rarely assessed among college students in Indonesia. This study aimed to assess the reliability and validity of the Mental Health Literacy Scale (MHLS) among late adolescents. Data for this study came from an online cross-sectional survey with first year college students from Universitas Hasanuddin, South Sulawesi $(n=347)$. Respondents were recruited through flyers and broadcast messages using quota by faculties. MHLS questionnaire was adapted using cognitive interview techniques with local college students to assess their comprehension on the items and the response options. The 25 items of MHLS showed a good reliability (Cronbach's Alpha $=0.77$ ) and has a positive association with Health Literacy Scale $(\alpha=0.71 ; p<0.001)$. Further analysis showed that the average converted score of MHLS were barely adequate $(M=60.72 ; S D=8.94)$. The findings suggested that the adapted MHLS is a reliable and valid instrument to measure mental health literacy among college students.
\end{abstract}

Keywords: college student; health communication; psychology

\begin{abstract}
Abstrak. Literasi kesehatan mental dapat menjadi tolok ukur kemampuan seseorang dalam memahami dan mengatasi masalah kesehatan mental pada dirinya sendiri dan lingkungan sosialnya. Namun, asesmen literasi kesehatan mental masih belum banyak dilakukan di Indonesia, khususnya di kalangan remaja akhir sebagai kelompok berisiko mengalami gangguan kesehatan mental. Penelitian ini bertujuan untuk menguji reliabilitas dan validitas dari instrumen literasi kesehatan mental (Mental Health Literacy Scale/MHLS) pada remaja akhir. Penelitian dengan desain potong lintang ini mengambil sampel berbasis proporsi mahasiswa tingkat pertama program sarjana reguler di semua fakultas yang ada di Universitas Hasanuddin ( $n=374)$. Responden direkrut melalui flyer dan pesan teks untuk mengikuti survei daring pada Juli 2019. Instrumen MHLS yang telah diterjemahkan ke dalam Bahasa Indonesia dan diadaptasi melalui wawancara kognitif terdiri dari 11 pertanyaan dengan skala 4, dan 14 pertanyaan dengan skala 5. Hasil pengujian menunjukkan MHLS memiliki reliabilitas yang baik (Alpha Cronbach $=0,77$ ) dan memiliki asosiasi yang positif dengan instrumen literasi kesehatan (Health Literacy Scale). Hasil analisis lanjutan menunjukkan rata-rata skor total responden setelah dikonversi ke skala 100 adalah 60,72 $(S D=8,94)$. Secara umum, hasil adaptasi mengindikasikan bahwa MHLS adalah instrumen yang valid dan reliabel untuk mengukur tingkat literasi kesehatan mental pada mahasiswa tingkat pertama.
\end{abstract}

Kata kunci: komunikasi kesehatan; mahasiswa; psikologi

${ }^{1}$ Korespondensi mengenai artikel ini dapat dilakukan melalui 
Secara global, prevalensi gangguan mental yang terjadi pada rentang umur 5-17 tahun sebesar 6,72\% dengan prevalensi gangguan mental di Asia Tenggara sendiri sebesar 4,47 persen (Erskine et al., 2017). Adapun di Indonesia, prevalensi gangguan mental yang terjadi pada remaja di atas umur 15 tahun meningkat dari $6 \%$ pada tahun 2013 menjadi 9,8\% pada 2018 (Kementerian Kesehatan Republik Indonesia, 2018).

Gangguan mental dipandang sebagai suatu perilaku yang menyimpang jika dibandingkan dengan perilaku masyarakat secara umum (Cockerham, 2016). Gangguan mental akan berdampak negatif pada akses pendidikan, produktivitas, akses terhadap keadilan hukum, dan bahkan akses terhadap layanan kesehatan (Bolton, 2008).

Jenis gangguan mental cukup beragam tergantung dari gejala yang dialami penderitanya, seperti gangguan kecemasan, anti sosial, alkoholisme, kleptomania, anorgosmia, narsistik, skizofrenia, dan sebagainya (Spitzer, Endicott, \& Micoulaud Franchi, 2018). Di Indonesia, jumlah kasus orang dengan gangguan mental yang dipasung (shackling) ada sekitar 18.000 kasus. Pemasungan dilakukan dengan cara mengikatnya di tempat tidur, atau dengan mengikat kakinya menggunakan pemberat (cement blocks), hingga dikurung dalam tempat yang menyerupai kandang hewan (Human Rights Watch, 2018).

Pasung merupakan salah satu bentuk kekerasan terhadap Hak Asasi Manusia dan bentuk ketidaksetaraan dalam kesehatan mental. Seseorang yang mengalami gangguan mental dan kemudian dipasung oleh keluarganya, mengindikasikan minimnya pengetahuan dan kemampuan keluarga untuk mengakses pelayanan kesehatan jiwa (Minas \& Diatri, 2008).

Konsep literasi kesehatan mental pertama kali dikembangkan oleh Jorm et al. (1997) yang didefinisikan sebagai pengetahuan dan keyakinan seseorang terhadap kondisi kelainan mental (mental disorder) yang dapat membantu mereka menyadari, mengatur, dan mencegah kelainan mental (Jorm et al., 1997). Literasi kesehatan mental yang baik dapat mengurangi stigma terhadap orang dengan gangguan jiwa, sehingga mereka akan cenderung mencari pertolongan yang tepat ketimbang mengurung ODGJ atau bahkan melakukan pemasungan (Holman, 2015).

Penelitian terdahulu menunjukkan bahwa orang yang memiliki pendidikan yang lebih tinggi, lebih mampu menyadari gangguan mental pada diri mereka dan orang lain, serta mencari pertolongan yang tepat (Reavley, McCann, \& Jorm, 2012). Selain itu, remaja yang memiliki kemampuan yang lebih baik dalam mendeteksi adanya depresi dan gangguan kecemasan pada dirinya maupun orang lain, akan merekomendasikan mencari pertolongan kepada teman, keluarga, dan konselor merupakan sumber pertolongan yang mereka rekomendasikan (Coles et al., 2016).

Penelitian di negara lain telah menunjukkan adanya hubungan positif antara literasi kesehatan mental terhadap pencarian pertolongan melalui anggota keluarga (White \& Casey, 2017). Selain itu, literasi kesehatan mental juga dijadikan sebagai prediktor terhadap perilaku 
pencarian pengobatan psikis di kalangan mahasiswa, di mana semakin baik literasi kesehatan mentalnya, maka mereka akan cenderung mencari pertolongan dengan mendatangi konselor serta mengabaikan stigma buruknya (Cheng, Wang, McDermott, Kridel, \& Rislin, 2018).

Literasi Kesehatan Mental diukur dengan menggunakan beberapa instrumen seperti Knowledge about Schizophrenia Questionnaire (KASQ) yang terdiri dari 25 pertanyaan pilihan ganda untuk menilai pengetahuan dan manajemen terkait schizophrenia (Ascher-Svanum \& Whitesel, 1999), Multiple-Choice Knowledge of Mental Illnesses Test (MC-KOMIT) yang terdiri dari 33 item untuk menilai pengetahuan tentang kelainan mental (Compton, Hankerson-dyson, \& Broussard, 2011), dan Depression Multiple Choice Question (MCQ) yang berisi 27 item untuk menilai pengetahuan tentang depresi (Gabriel \& Violato, 2009).

Selain itu, ada juga instrumen Test of Knowledge About ADHD yang terdiri dari 22 item untuk menilai pengetahuan dan sikap dalam menghadapi murid dengan ADHD (Hepperlen, Clay, Henly, Barké, 1983), Mental Health Literacy Scale (MHLS) yang digunakan untuk menilai pengetahuan dan sikap tentang pencarian pengobatan dan kesadaran akan gangguan mental, serta masih banyak lainnya (Wei, McGrath, Hayden, \& Kutcher, 2016).

MHLS memiliki enam atribut yang terkandung dalam 26 item dalam instrumen. Atribut tersebut meliputi; kemampuan untuk menyadari kelainan mental, pengetahuan untuk mengakses informasi, pengetahuan tentang faktor risiko dan penyebabnya, pengetahuan tentang pertolongan pada diri sendiri, pengetahuan tentang tenaga profesional yang tersedia, dan sikap serta perilaku yang tepat dalam pencarian pengobatan (O'Connor \& Casey, 2015).

Tentunya, setiap instrumen harus valid dan reliabel agar bisa dijadikan alat ukur pada suatu populasi. Dalam studi kuantitatif, ketepatan suatu penelitian dipengaruhi oleh evaluasi terhadap validitas dan reliabilitas alat ukur yang digunakan pada penelitian. Validitas merujuk pada konsep yang akurat terukur, sedangkan reliabilitas merujuk pada keakuratan suatu alat ukur (Heale \& Twycross, 2015). Penelitian ini bertujuan untuk mengetahui reliabilitas dan validitas dari Mental Health Literacy Scale (MHLS) pada kalangan mahasiswa tingkat pertama di Universitas Hasanuddin.

\section{Metode}

Jenis penelitian

Penelitian observasional ini dilakukan dengan menggunakan desain potong lintang (cross sectional) yang menghitung dampak dan paparan dalam satu waktu yang sama (Setia, 2016).

\section{Populasi dan sampel}

Populasi pada penelitian ini adalah mahasiswa yang masih aktif berkuliah di Universitas Hasanuddin, khususnya mahasiswa tingkat pertama program sarjana reguler. Pengambilan sampel penelitian dilakukan dengan menghitung proporsi mahasiswa tingkat pertama program sarjana reguler di semua fakultas yang ada di Universitas Hasanuddin $(n=374)$. 
Teknik pengambilan sampel dan data

Responden direkrut melalui flyer elektronik dan pesan teks yang disebar pada Juli 2019 melalui koordinator angkatan di tingkat fakultas. Pesan yang disebar berisi ajakan untuk berpartisipasi dalam survei daring (online) dengan membagikan tautan ke aplikasi kuesioner dari Survei Gizmo. Responden yang ikut berpartisipasi dalam penelitian ini diberikan insentif dalam bentuk voucher pulsa sebagai bentuk penghargaan atas partisipasi mereka.

\section{Pengukuran dan analisis data}

Literasi kesehatan mental sebagai variabel utama dalam penelitian ini diukur dengan instrumen MHLS yang telah diadaptasi melalui diadaptasi melalui wawancara kognitif yang terdiri dari 11 pertanyaan dengan skala 4 dan 14 pertanyaan dengan skala 5.

MHLS mengukur aspek pengetahuan perihal kondisi kelainan mental dan sikap yang mendukung perilaku pencarian pengobatan yang tepat. MHLS terdiri enam atribut yang tersebar pada 26 aitem yang terdiri dari kemampuan untuk menyadari kelainan mental (6), pengetahuan untuk mengakses informasi (3), pengetahuan tentang faktor risiko dan penyebabnya (1), pengetahuan tentang pertolongan pada diri sendiri (1), pengetahuan tentang tenaga profesional yang tersedia (3), dan sikap yang tepat dalam mendukung pencarian pengobatan (11).

Pilihan respons subjek penelitian pada instrumen ini berupa skala likert.
Beberapa aitem yang merujuk pada pengetahuan, memiliki respons subjek yang terdiri dari 'sangat mungkin' hingga 'sangat tidak mungkin'. Selain itu, beberapa aitem lainnya yang merujuk pada sikap, memiliki respons subjek yang terdiri dari 'sangat setuju' hingga 'sangat tidak setuju'.

Literasi kesehatan sebagai variabel pembanding diukur dengan instrumen HLS-EU-Q16 yang digunakan untuk mengukur literasi kesehatan pada suatu populasi (Storms, Claes, Aertgeerts, \& Van Den Broucke, 2017). HLS-EU-Q16 merupakan instrumen yang mengukur tiga dimensi yang terdiri dari akses terhadap pelayanan kesehatan (7), pencegahan (5), dan promosi kesehatan (4). Adapun pilihan respons subjek pada instrumen ini masih berupa skala likert yang terdiri dari 'sangat mudah' hingga 'sangat sulit'. Adapun variabel sosiodemografi yang diukur dalam penelitian ini meliputi jenis kelamin, fakultas, serta pendapatan berdasarkan uang jajan mingguan.

Analisis univariat dilakukan untuk menguji reliabilitas instrumen dengan Alpha Cronbach. Jika nilai $\alpha \geq 0,6$ maka instrumen layak dikategorikan sebagai instrumen yang reliabel (Cortina, 1993).

Analisis bivariat dilakukan untuk menemukan bukti validitas berdasarkan korelasinya dengan variabel lain yang relevan. Variabel yang dimaksud dalam penelitian ini adalah literasi kesehatan mental dan literasi kesehatan. Variabel ini dipilih sebagai kriteria karena kedua variabel ini mengukur pengetahuan dan sikap terkait kesehatan walaupun dalam konteks yang berbeda antara kesehatan secara umum dan kesehatan mental. Hal 


\section{PONGTAMBING et al.}

tersebut membuat kedua variabel ini memiliki korelasi yang positif. Seluruh data diolah dan dianalisis dengan menggunakan aplikasi STATA versi 16.

\section{Hasil}

Responden dalam penelitian ini merupakan mahasiswa tingkat pertama Universitas Hasanuddin ( $\mathrm{n}=374$ ) yang proporsional dengan populasi berdasarkan usia, fakultas, jenis kelamin dan tingkat ekonomi (lihat Tabel 1).

Skor MHLS diperoleh dari penjumlahan skor seluruh jawaban terhadap 25 aitem, ini menghasilkan rentang nilai terendah $=25$ hingga tertinggi $=114$. Hasil penjumlahan total skor dari tiap responden kemudian dikonversi ke skala 0-100 dengan mengurangi total skor dengan 25 kemudian mengalikannya dengan 100/89. Hasil rata-rata dari total skor yang telah dikonversi adalah 59,59 (SD=8,68) dengan nilai terendah $=34,83$ dan tertinggi $=82,02$.

Dari segi daya beda aitem yang dapat dilihat melalui nilai corrected itemtotal correlation, sebagian besar aitem memiliki nilai diatas nilai $r$ kritis $(0,30)$. Adapun beberapa aitem $(1,3,6,7,11,12$, $13,14,16$, dan 18) yang memiliki nilai di bawah $\mathrm{r}$ kritis merupakan aitem reversed coded.

Hasil uji reliabilitas menunjukkan Alpha Cronbach sebesar 0,77. Sementara

Tabel 1

Karakteristik Responden

\begin{tabular}{lcc}
\multicolumn{1}{c}{ Karakteristik Responden } & $\begin{array}{c}\text { Jumlah } \\
(\mathbf{n})\end{array}$ & Persentase (\%) \\
& & \\
\hline Semua Responden & 374 & 100 \\
\hline Jenis Kelamin & & \\
Laki - laki & 142 & 38 \\
Perempuan & 232 & 62 \\
\hline Fakultas & & \\
Ekonomi dan Bisnis & 27 & 7,2 \\
Hukum & 14 & 3,7 \\
Sospol & 32 & 8,5 \\
Ilmu Budaya & 24 & 6,4 \\
Kedokteran & 29 & 7,7 \\
Kedokteran Gigi & 10 & 2,6 \\
Keperawatan & 16 & 4,2 \\
Kesehatan Masyarakat & 18 & 4,8 \\
Ilmu Kelautan dan Perikanan & 26 & 6,9 \\
Kehutanan & 17 & 4,5 \\
Peternakan & 23 & 6,1 \\
Pertanian & 29 & 7,7 \\
MIPA & 35 & 9,3 \\
Farmasi & 8 & 2,1 \\
Teknik & 66 & 17,6 \\
\hline Pendapatan (Uang saku mingguan) & & \\
Rendah (< Rp 300.000) & 277 & 74 \\
Tinggi (>Rp 300.000) & 97 & 26 \\
& & \\
\hline 214 & & E-JOURNAL GAMAJOP
\end{tabular}


hasil uji validitas dilakukan dengan melihat asosiasi antara MHLS dengan HLS sebagai variabel dengan konstruk yang senada menunjukkan hasil $r=0,219$ dengan $p<0,001$.

\section{Diskusi}

Penelitian ini mengambil data berbasis kuota sehingga proporsional dengan populasi yang menjadi target, yakni mahasiswa tingkat pertama di Universitas Hasanuddin. Dari sisi instrumen, penelitian ini mengadaptasi MHLS dengan melakukan translasi serta revisi ke dalam bahasa dan konteks budaya Indonesia. Kemudian diikuti dengan pengujian keterbacaan dan pemahaman melalui teknik wawancara kognitif terhadap partisipan yang mewakili karakteristik responden untuk penelitian ini.

Secara umum, rata-rata total skor MHLS dari seluruh responden adalah $59,59(\mathrm{SD}=8,68)$ yang jika dilihat dari rentang skala 0-100 masuk ke dalam kategori sedang (moderat). Hasil ini serupa dengan penelitian yang dilakukan pada mahasiswa di Inggris yang menunjukkan nilai rata-rata literasi kesehatan mental sebesar 123 dari rentang 87-160 (Paul, 2017) dan penelitian di Saudi Arabia yang menunjukkan lebih dari 90\% mahasiswa disana memiliki tingkat literasi kesehatan mental yang tergolong dalam kategori moderat (Mahfouz et al., 2016) sehingga masih sangat memungkinkan untuk melakukan intervensi dalam bentuk edukasi kesehatan mental untuk mahasiswa.

Namun hasil ini tidak sejalan dengan penelitian serupa yang dilakukan pada kalangan muda di Norwegia yang mendapatkan nilai rata-rata literasi kesehatan mental sebesar 4,51 dari rentang skala 0-5, atau sudah menunjukkan literasi kesehatan yang sangat baik (Bjørnsen et al., 2017). Beberapa penelitian mencoba membandingkan literasi kesehatan mental pada mahasiswa domestik dan mahasiswa internasional. Salah satunya penelitian yang dilakukan di Australia. Hasil penelitiannya menunjukkan bahwa mahasiswa domestik memiliki literasi kesehatan mental yang lebih baik dibandingkan dengan literasi kesehatan mental pada mahasiswa internasional. Hasil ini menjadi dasar untuk melakukan intervensi khususnya pada mahasiswa internasional di Australian University (Clough, Nazareth, Day, \& Casey, 2019)

Literasi kesehatan mental juga telah diteliti di Australian National University namun penelitian dilakukan dengan mengambil staf akademik sebagai responden penelitiannya. Hasil penelitiannya menunjukkan bahwa nilai literasi kesehatan mental staf akademik adalah 13,78 dari rentang 0-22. Penelitian ini juga menunjukkan bahwa staf akademik yang memiliki latar belakang ilmu kesehatan memiliki literasi kesehatan mental yang lebih baik dibandingkan dengan staf akademik yang tidak memiliki latar belakang ilmu kesehatan (Gulliver, Farrer, Bennett, \& Griffiths, 2019).

Penelitian serupa juga dilakukan di Amerika Serikat pada mahasiswa yang berjenis kelamin laki-laki yang menunjukkan bahwa MHLS merupakan instrumen yang valid digunakan pada kalangan mahasiswa (Rafal, Gatto, \& Debate, 2018). 
Pada penelitian ini, hasil uji korelasi antara MHLS dengan HLS menunjukkan hubungan positif yang signifikan, sesuai dengan ekspektasi uji validitas di awal. Artinya, MHLS dapat digunakan sebagai instrumen untuk mengukur literasi kesehatan mental dikalangan mahasiswa. Korelasi positif antara MHLS dan HLS menggambarkan bahwa orang dengan literasi kesehatan mental yang baik, tentunya memiliki literasi kesehatan yang baik pula.

Daya beda tiap aitem pada alat ukur ini menunjukkan bahwa sebagian besar aitem valid karena memiliki nilai di atas nilai r kritis (Sarwono, 2014). Adapun beberapa aitem yang memiliki nilai di bawah nilai $r$ kritis merupakan aitem reversed coded. Reversed coded merupakan skor yang memiliki nilai yang berlawanan arah. Reversed coded dilakukan untuk mengurangi kesalahan respons dalam suatu instrumen (Suárez-Alvarez et al., 2018).

Hasil uji reliabilitas MHLS juga mendapatkan bahwa instrumen ini reliabel $(\alpha=0,77)$ digunakan pada kalangan mahasiswa dalam penelitian ini dan memiliki konsistensi internal yang baik. Konsistensi internal yang baik pada penelitian ini merujuk pada keandalan MHLS untuk mengukur literasi kesehatan mental dikalangan mahasiswa secara konsisten.

Hal ini sejalan dengan penelitian yang dilakukan pada kalangan muda di Portugis, yang mendapatkan hasil bahwa MHLS adalah instrumen yang valid dan reliabel (Dias, Campos, Almeida, \& Palha, 2018). MHLS juga reliabel di kalangan mahasiswa khususnya mahasiswa dengan latar belakang kesehatan. Penelitian dilakukan di Taiwan pada kalangan mahasiswa di universitas yang berbeda. Hasil penelitian menunjukkan bahwa MHLS merupakan instrumen yang reliabel pada kalangan mahasiswa di Taiwan dan memiliki internal konsistensi yang baik (Chao et al., 2020).

Tidak hanya di kalangan mahasiswa saja, namun MHLS juga diuji cobakan pada kalangan tenaga pendidik di Amerika Serikat dan mendapatkan bahwa MHLS adalah instrumen yang reliabel dan memiliki internal konsistensi yang baik (Kenney, 2019). Penelitian serupa dilakukan pula pada tenaga kesehatan tingkat pertama di Zambia dan Afrika Selatan dengan menganalisis masingmasing pertanyaan secara lebih rinci. Dari penelitian tersebut ditemukan bahwa MHLS valid dan reliabel digunakan di kalangan tenaga kesehatan di Zambia dan Afrika Selatan (Korhonen, Axelin, Grobler, \& Lahti, 2019).

Penelitian ini memiliki beberapa keterbatasan yang patut dipahami dalam menginterpretasi hasilnya. Pertama, responden dalam penelitian ini diambil berbasis kesediaan responden, bukan dengan cara acak sederhana. Kami mencoba mengatasi keterwakilan dengan menggunakan kuota di tingkat fakultas. Namun hal ini tetap berdampak pada generalisasi hasil ke tingkat populasi. Kedua, penelitian ini dilakukan pada akhir semester kedua sehingga responden sudah melalui tahun pertama dari perkuliahan. Mungkin hasil penelitian akan berbeda jika dilakukan pada semester pertama dimana masih belum banyak berinteraksi di kampus. 


\section{Kesimpulan}

Mental Health Literacy Scale (MHLS) merupakan instrumen yang reliabel untuk mengukur tingkat literasi kesehatan mental di kalangan mahasiswa program sarjana Universitas Hasanuddin berdasarkan sudut pandang konsistensi internal. Instrumen ini valid berdasarkan kriteria korelasi dengan variabel literasi kesehatan. Mahasiswa Universitas Hasanuddin memiliki nilai literasi kesehatan mental yang moderat (sedang) dan masih memerlukan program lanjutan untuk meningkatkannya.

\section{Implikasi}

Instrumen MHLS layak diuji coba pada mahasiswa di universitas lain. Hasil dari asesmen dapat digunakan untuk mengembangkan program edukasi yang dapat meningkatkan literasi kesehatan mental mahasiswa.

Acknowledgments: Penelitian ini didanai oleh Direktorat Riset dan Pengabdian Masyarakat, Universitas Indonesia (DPRM-UI)

Kontribusi Penulis: DA menyusun desain penelitian dan mengalihbahasakan instrumen menjadi bahasa Indonesia. YSP mengumpulkan data dan menyusun manuskrip. YS mengumpulkan data dan menyusun desain penelitian. WOSA menyusun desain penelitian dan mendistribusikan instrumen pada responden. YF menyusun desain penelitian dan mendistribusikan instrumen pada responden. Semua pengararang melakukan analisis data dan bersama-sama menyepakati manuskrip versi akhir.

\section{Daftar Pustaka}

Ascher-Svanum, H., \& Whitesel, J. (1999). A randomized controlled study of two styles of group patient education about schizophrenia. Psychiatric Services, 50(7), 926-930. doi: https://doi.org/10.1176/ps.50.7.926

Bjørnsen, H. N., Elizabeth, M., Eilertsen, B., Ringdal, R., Espnes, G. A., \& Moksnes, U. K. (2017). Positive mental health literacy: Development and validation of a measure among Norwegian adolescents. BMC Public Health, 17, 1-10. doi: https://doi.org/10.1186/s12889-017$\underline{4733-6}$

Bolton, D. (2008). What is mental disorder?: An essay in philosophy, science, and values. Oxford: Oxford University Press.

Chao, H., Lien, Y., Kao, Y., Tasi, I., Lin, H., Lien, Y. (2020). Mental health literacy in healthcare students: An expansion of the Mental Health Literacy Scale. International Journal of Environmental Research and Public Health, 17(3), 1-15. doi:

https://doi.org/10.3390/ijerph17030948 Cheng, H. L., Wang, C., McDermott, R. C., Kridel, M., \& Rislin, J. L. (2018). Selfstigma, mental health literacy, and attitudes toward seeking psychological help. Journal of Counseling and Development, 96(1), 6474. doi:

https://doi.org/10.1002/jcad.12178 
Clough, B. A., Nazareth, S. M., Day, J. J., \& Casey, L. M. (2019). A comparison of mental health literacy, attitudes, and help-seeking intentions among domestic and international tertiary students. British Journal of Guidance and Counselling, 47(1), 123-135. doi: https://doi.org/10.1080/03069885.2018. $\underline{1459473}$

Cockerham, W. C. (2016). Sociology of mental disorder. Oxfordshire: Taylor \& Francis.

Coles, M. E., Ravid, A., Gibb, B., GeorgeDenn, D., Bronstein, L. R., \& McLeod, S. (2016). Adolescent mental health literacy: Young people's knowledge of depression and social anxiety disorder. Journal of Adolescent Health, 58(1), 57-62. doi: https://doi.org/10.1016/j.jadohealth.20 $\underline{15.09 .017}$

Compton, M. T., Hankerson-Dyson, D., \& Broussard, B. (2011). Development, item analysis, and initial reliability and validity of a multiple-choice knowledge of mental illnesses test for lay samples. Psychiatry Research, 189(1), 141-148. doi: https://doi.org/10.1016/j.psychres.2011 .05 .041

Cortina, J. M. (1993). What is coefficient alpha? An examination of theory and applications. Journal of Applied Psychology, 78(1), 98-104. doi: https://doi.org/10.1037/0021$\underline{9010.78 .1 .98}$

Dias, P., Campos, L., Almeida, H., \& Palha, F. (2018). Mental health literacy in young adults: Adaptation and psychometric properties of the mental health literacy questionnaire.
International Journal of Environmental Research and Public Health, 15(7), 1-13. doi:

https://doi.org/10.3390/ijerph15071318 Erskine, H. E., Baxter, A. J., Patton, G., Moffitt, T. E., Patel, V., Whiteford, H. A., \& Scott, J. G. (2017). The global coverage of prevalence data for mental disorders in children and adolescents. Epidemiology and Psychiatric Sciences, 26(4), 395-402. doi: https://doi.org/10.1017/S204579601500 $\underline{1158}$

Gabriel, A., \& Violato, C. (2009). The development of a knowledge test of depression and its treatment for patients suffering from non-psychotic depression: A psychometric assessment. BMC Psychiatry, 15, 1-15. doi: https://doi.org/10.1186/1471-244X$\underline{9-56}$

Gulliver, A., Farrer, L., Bennett, K., \& Griffiths, K. M. (2019). University staff mental health literacy, stigma and their experience of students with mental health problems. Journal of Further and Higher Education, 43(3), 434-442.

doi:

https://doi.org/10.1080/0309877X.2017. $\underline{1367370}$

Heale, R., \& Twycross, A. (2015). Validity and reliability in quantitative studies. Evidence-Based Nursing, 18(3), 66-67. doi: https://doi.org/10.1136/eb-2015$\underline{102129}$

Hepperlen, T. M., Clay, D. L., Henly, G. A., Barké, C. R. (1983). Measuring teacher attitudes and expectations toward students with ADHD: development of the test of knowledge about ADHD (KADD). Journal of Attention Disorder, 
5(3), $\quad$ 133-142. doi: https://doi.org/10.1177/1087054702005 $\underline{00301}$

Holman, D. (2015). Exploring the relationship between social class, mental illness stigma and mental health literacy using British national survey data. Health: An Interdisciplinary Journal for the Social Study of Health, Illness and Medicine, 19(4), 413-429. doi: https://doi.org/10.1177/1363459314554 $\underline{316}$

Human Rights Watch. (2018). End shackling in Indonesia. Diakses melalui https://www.hrw.org/breakthechains

Jorm, A. F., Korten, A. E., Jacomb, P. A., Christensen, H., Rodgers, B., \& Pollitt, P. (1997). "Mental health literacy": A survey of the public's ability to recognise mental disorders and their beliefs about the effectiveness of treatment. Medical Journal of Australia, 166(4), 182-186. doi: https://doi.org/10.5694/j.13265377.1997.tb140071.x

Kenney, C. A. (2019). An examination of the psychometric properties of the Mental Health Literacy Scale with K-12 educators (Disertasi tidak dipublikasikan). School of Education, George Fox University.

Korhonen, J., Axelin, A., Grobler, G., \& Lahti, M. (2019). Content validation of Mental Health Literacy Scale (MHLS) for primary health care workers in South Africa and Zambia - a heterogeneous expert panel method. Global Health Action, 12(1), 1-12. doi: https://doi.org/10.1080/16549716.2019. $\underline{1668215}$
Kementerian Kesehatan Republik Indonesia. (2018). Hasil Utama Riskesdas 2018. Jakarta: Kementerian Kesehatan Republik Indonesia.

Mahfouz, M. S., Aqeeli, A., Makeen, A. M., Hakami, R. M., Najmi, H. H., Mobarki, A. T., ... Ageel, O. A. (2016). Mental health literacy among undergraduate students of a Saudi tertiary institution: A cross-sectional study. Mental Illness, 8(2), 35-39.

Minas, H., \& Diatri, H. (2008). Pasung: Physical restraint and confinement of the mentally ill in the community. International Journal of Mental Health Systems, 2,8. doi: https://doi.org/10.1186/1752-4458-2-8

O'Connor, M., \& Casey, L. (2015). The Mental Health Literacy Scale (MHLS): A new scale-based measure of mental health literacy. Psychiatry Research, 229(1-2), 511-516. doi: https://doi.org/10.1016/j.psychres.2015 .05 .064

Paul, G. (2017). Examining mental health literacy, help seeking behaviours, and mental health outcomes in UK university students. The Journal of Mental Health Training, Education and Practice, 12(2), 111-120. doi: https://doi.org/10.1108/JMHTEP-052016-0027

Rafal, G., Gatto, A., \& Debate, R. (2018). Mental health literacy, stigma, and help-seeking behaviors among male college students. Journal of American College Health, 66(4), 284-291. doi: https://doi.org/10.1080/07448481.2018. $\underline{1434780}$

Reavley, N. J., McCann, T. V., \& Jorm, A. F. (2012). Mental health literacy in 
higher education students. Early Intervention in Psychiatry, 6(1), 45-52. doi: $\quad$ https://doi.org/10.1111/j.1751$\underline{7893.2011 .00314 . x}$

Sarwono, J. (2014). Path analysis dengan SPSS. Jakarta: Elex Media Komputindo.

Setia, M. S. (2016). Methodology Series Module 3: Cross-sectional Studies. Indian Journal of Dermatology, 61(3), 261-264.

doi:

https://doi.org/10.4103/0019-

$\underline{5154.182410}$

Spitzer, R. L., Endicott, J., \& Micoulaud Franchi, J. A. (2018). Medical and mental disorder: Proposed definition and criteria. Annales MedicoPsychologiques, 176(7), 656-665. doi: https://doi.org/10.1016/j.amp.2018.07.0 $\underline{04}$

Storms, H., Claes, N., Aertgeerts, B., \& Van Den Broucke, S. (2017). Measuring health literacy among low literate people: an exploratory feasibility study with the HLS-EU questionnaire.
BMC Public Health, 17, 1-10. doi: https://doi.org/10.1186/s12889-017$\underline{4391-8}$

Suárez-Alvarez, J., Pedrosa, I., Lozano, L. M., García-Cueto, E., Cuesta, M., \& Muñiz, J. (2018). Using reversed items in Likert scales: A questionable practice. Psicothema, 30(2), 149-158. doi:

https://doi.org/10.7334/psicothema201 $\underline{8.33}$

Wei, Y., McGrath, P. J., Hayden, J., \& Kutcher, S. (2016). Measurement properties of tools measuring mental health knowledge: A systematic review. BMC Psychiatry, 16, 1-16. doi: https://doi.org/10.1186/s12888-016$\underline{1012-5}$

White, M., \& Casey, L. (2017). Helping older adults to help themselves: the role of mental health literacy in family members. Aging and Mental Health, 21(11), 1129-1137. doi: https://doi.org/10.1080/13607863.2016. $\underline{1206513}$ 